\title{
Long term results of radiotherapy for subfoveal choroidal neovascularisation in age related macular degeneration
}

\author{
Martine Mauget-Faÿsse, Christophe Chiquet, Dan Milea, Pascale Romestaing, \\ Jean-Pierre Gérard, Philippe Martin, Françoise Koenig
}

\begin{abstract}
Backgroundlaims-Radiotherapy has been proposed as an alternative treatment for patients with subfoveal choroidal neovascularisation ( $\mathrm{CNV}$ ) that is untreatable according to macular photocoagulation study guidelines. This prospective study was designed to evaluate whether radiotherapy may affect the functional and anatomical outcome in a large cohort of patients affected by subfoveal $\mathrm{CNV}$, with a follow up period up to 24 months.

Methods-212 patients (231 eyes) with newly diagnosed subfoveal CNV not amenable to laser therapy were included in this study. Two radiotherapy methods, the lateral beam technique (6 MV, $20 \mathrm{~Gy}$ in five fractions) and lateral arc therapy (25 $\mathrm{MV}, 16$ to $20 \mathrm{~Gy}$, in four or five fractions), were used. Comparisons of best corrected visual acuity (VA), fluorescein (FA) and indocyanine green (ICG) angiography, at inclusion and $6,12,18$, and 24 months after radiotherapy were performed using univariate analysis.

Results-A VA improvement of two or more lines was observed in $34 \%$ at 12 months, $31 \%$ at 18 months, and $32 \%$ of the eyes at $\mathbf{2 4}$ months. Paired comparisons of CNV areas in FA and ICG showed no significant change between baseline and each visit. However, 12 and 18 months after treatment, $47 \%$ of the eyes showed a decrease of $10 \%$ or more in CNV size both in ICG and FA. Radiation side effects included radiation retinopathy (eight eyes), optic neuropathy (four eyes), choroidal vasculopathy (five eyes), and branch retinal vein occlusion (three eyes). Conclusion-Compared with the natural course of subfoveal CNV, the results of this prospective study suggest that radiotherapy could stabilise visual and anatomical outcome in selected cases. (Br f Ophthalmol 1999;83:923-928)
\end{abstract}

Centre d'Imagerie et de Laser, Lyons, France

M Mauget-Faÿsse

Service

d'Ophtalmologie,

Hôpital Edouard

Herriot, Lyons, France

C Chiquet

D Milea

Service de

Radiothérapie, Centre

Hospitalier Lyon-Sud,

Lyons, France

P Romestaing

J-P Gérard

Service de

Radiothérapie,

Clinique Saint-Jean,

Lyons, France

P Martin

Service

d'Ophtalmologie, Hôpital Bellevue, Saint-Etienne, France

F Koenig

Correspondence to:

Martine Mauget-Faÿsse,

$\mathrm{MD}$, Centre d'Imagerie et de

Laser, 14 Rue Rabelais,

69003 Lyon, France.

Accepted for publication 12 March 1999
Age related macular degeneration (AMD) is the leading cause of visual loss in industrialised countries. ${ }^{12}$ Legal blindness in AMD is related to choroidal neovascularisation (CNV) in $90 \%$ of these patients. ${ }^{3}$ Laser photocoagulation is the effective treatment for visible CNV located at $200 \mu \mathrm{m}$ or more from the centre of the foveal avascular zone. ${ }^{4-7}$ Nevertheless, laser photocoretina and therefore significant visual loss agulation results in destruction of the overlying immediately following therapy. ${ }^{8}$ Besides, laser therapy of classic neovascularisation associated with occult $\mathrm{CNV}$ has been considered not beneficial. ${ }^{9}$ Ionising radiation has been reported as an alternative treatment of subfoveal $\mathrm{CNV}$, either by external beam ${ }^{10-19}$ or by plaque radiotherapy. ${ }^{20}$ Comparisons of results are difficult because radiation dose levels. ${ }^{21}$ The purpose of this study was to investigate whether radiotherapy may affect functional and anatomical outcome in a large cohort of patients affected by subfoveal CNV, with a 12-24 month follow up period.

\section{Patients and methods}

Two hundred and twelve patients (231 eyes) with age related subfoveal CNV, not eligible for laser photocoagulation treatment according to macular photocoagulation study guidelines, ${ }^{6}$ were enrolled in this prospective study between September 1995 and October 1997.

\section{ELIGIBILITY CRITERIA}

Patients of 55 years of age or older with newly diagnosed active subfoveal CNV not amenable to laser therapy were included in this study. All the patients complained of metamorphopsia or recent progressive decrease of visual acuity (VA), with a delay equal to or less than 6 months. Diagnosis of subfoveal CNV membranes was confirmed using fluorescein (FA) and indocyanine green (ICG) angiographies. Three subgroups of patients were defined: classic CNV without occult, occult CNV without classic, and classic associated with occult CNV. Radiotherapy was delivered after the patient's informed consent.

\section{EXCLUSION CRITERIA}

Patients were excluded for any of the following reasons: CNV associated with myopia or other macular disease, CNV previously treated by laser therapy, systemic vasculopathy such as diabetes mellitus or uncontrolled systemic hypertension, or previous radiotherapy for ocular or cerebral malignancies.

\section{RADIOTHERAPY}

Two radiotherapy methods were used - the lateral beam and the arc therapy techniques. The lateral beam technique, previously described by Chakravarthy et $a l,{ }^{10}$ used a single $6 \mathrm{MV}$ photon beam with hemicircular collimation. The $95 \%$ isodose curve dimensions were 30 and $11 \mathrm{~mm}$, respectively. To avoid lens irradiation, the anterior front of the $50 \%$ isodose was 
Table 1 Visual acuity and frequency of distorted vision at baseline, 6, 12, 18, and 24 months

\begin{tabular}{llllll}
\hline & $\begin{array}{l}\text { Initial visit } \\
\text { No (\%) of eyes }\end{array}$ & $\begin{array}{l}\text { At 6 months } \\
\text { No (\%) of eyes }\end{array}$ & $\begin{array}{l}\text { At 12 months } \\
\text { No (\%) of eyes }\end{array}$ & $\begin{array}{l}\text { At 18 months } \\
\text { No (\%) of eyes }\end{array}$ & $\begin{array}{l}\text { At 24 months } \\
\text { No (\%) of eyes }\end{array}$ \\
\hline Visual acuity: & & & & & \\
$\quad<20 / 200$ & $50 / 231(21.6)$ & $45 / 231(19.4)$ & $31 / 154(20.1)$ & $21 / 94(22.3)$ & $11 / 55(20)$ \\
$20 / 200-20 / 50$ & $144 / 231(62.4)$ & $137 / 231(59.3)$ & $90 / 154(58.4)$ & $47 / 94(50)$ & $29 / 55(52.7)$ \\
$\quad 20 / 40-20 / 25$ & $37 / 231(16)$ & $49 / 231(21.2)$ & $33 / 154(21.5)$ & $26 / 94(27.6)$ & $15 / 55(27.2)$ \\
Metamorphopsia: & $187 / 231(80.9)$ & $81 / 231(35)$ & $33 / 154(21.4)$ & $14 / 94(14.8)$ & $10 / 55(18.1)$ \\
A <20/200 & $28 / 231(12.1)$ & $15 / 231(6.5)$ & $6 / 154(3.9)$ & $3 / 94(3.2)$ & $1 / 55(1.8)$ \\
A $\geqslant 20 / 200$ & $159 / 231(68.8)$ & $66 / 231(28.5)$ & $27 / 154(17.5)$ & $11 / 94(11.7)$ & $9 / 55(16.3)$ \\
\hline
\end{tabular}

positioned $2 \mathrm{~mm}$ behind the posterior capsule. In 72 eyes, 20 Gy were delivered in five fractions, on 5 consecutive days (effective dose of $30 \mathrm{~Gy}$ ).

The lateral arc therapy used a $25 \mathrm{MV}$ photon minibeam in 159 eyes. This method delivered irradiation with a high energy photon beam superimposed on orbital computed tomography scan images. Beam diameter varied between 14 and $18 \mathrm{~mm}$ and was adjusted according to the CNV area measured on FA and ICG images. The total dose of 16-20 Gy (in four or five fractions, respectively) - that is, an effective and equivalent dose of 24 and 30 Gy respectively, was delivered on the pathological macular area. Beam distribution affected less than $5 \%$ of the lens and of the contralateral ocular structures.

Laser treatment was performed in the following two cases: when choroidal telangiectasia were diagnosed on ICG angiographies during follow up; and when an increase of over $20 \%$ in CNV area was noted on FA and ICG images, with VA less than 20/200.

\section{CLINICAL EVALUATION}

Baseline data were age, best corrected VA, Amsler test, biomicroscopic findings, intraocular pressure, fluorescein and ICG angiographies. Best corrected VA measured on the early treatment diabetic retinopathy study chart ${ }^{22}$ and presence of metamorphopsia were recorded at the initial examination and at visits 6 , $12,18,24$ months after radiotherapy. Visual acuity was considered as improved if there was an increase of two lines or more. ${ }^{913}$ Mean VA was calculated using $\log M A R$ values. At each visit, contrast sensitivity of the treated eye was measured using the Pelli-Robson letter chart. ${ }^{23}$ The test was performed in photopic conditions, with best correction, the chart at a distance of 1 metre. Improvement was defined as progression of contrast sensitivity of at least one log step on the Pelli-Robson chart.

The 46 patients with bilateral subfoveal $\mathrm{AMD}$ and who underwent radiotherapy in the second involved eye answered a visual function questionnaire 18 months after treatment.

FLUORESCEIN AND ICG ANGIOGRAPHY

FA and ICG angiographies were performed before radiation therapy, 6, 12, 18, and 24 months after radiotherapy. Digital angiographies were obtained with the Topcon angiograph. CNV areas were measured both in FA and ICG late phase images with the IMAGE-NET software. Macular photocoagulation study criteria $^{9}$ were used to classify the $\mathrm{CNV}$ in angiographic images. Presence of pigment epi- thelial detachment (PED), exudates, haemorrhages, and retinal pigment epithelium atrophy was recorded. CNV size evolution was assessed using the following ratio: [(final area - initial area)/initial area] $\times 100$. We used this ratio to analyse paired comparisons of $\mathrm{CNV}$ areas between two follow up visits. Results obtained with this analysis method were independent of the patient's refraction, and allowed assessment of CNV course. Changes of CNV area were thus considered significant when growth or reduction of at least $10 \%$ of the initial area was observed.

STATISTICAL ANALYSIS

Statistical analysis was performed using the Statistical Package for the Social Science program (SPSS). Comparisons on qualitative factors before and after radiotherapy were analysed by $\chi^{2}$ analysis (incorporating Yates's correction). The Wilcoxon matched pairs signed rank test was used to compare VA and angiographic $\mathrm{CNV}$ areas, at different follow up times. The arithmetic difference in VA was computed as: follow up - baseline (initial logMAR - final $\log M A R)$. Mean comparisons of VA and CNV areas were tested using the Mann-Whitney-Wilcoxon rank sum W test, considering the two radiotherapy techniques and the two CNV groups (occult $v$ mixed). Follow up beyond 12 months was incomplete and tests were performed using case by case exclusion of missing data. p Values below 0.05 were regarded as significant using two tailed tests.

\section{Results}

Two hundred and twelve patients (231 eyes) were included in the study. There were 144 female $(68 \%)$ and 68 male $(32 \%)$ patients. The mean age of patients was 77 years (range 56-95 years). There were 116 right eyes $(50.2 \%)$. In 145 patients $(62.8 \%)$, the contralateral eye was already affected by AMD. At the scheduled follow up visits $(6,12,18$, and 24 months), data were available in $231,154,94$, and 55 eyes, respectively. CNVs were classified as occult in $71.4 \%$ (165/231 eyes), mixed in $26 \%$ (60 eyes), and classic in $2.6 \%$ (six eyes).

VISUAL OUTCOME AT 6, 12, 18 AND 24 MONTH EXAMINATION

The distribution of VA and metamorphopsia at baseline and at the follow up visits are presented in Table 1. A statistical difference was found between initial VA and VA at each follow up visit. VA changes during the study are listed in Table 2. An improvement of two or more lines was observed in $31 \%$ at 18 months 
Table 2 Visual outcome 6,12, 18, and 24 months after radiotherapy

\begin{tabular}{lllll}
\hline & $\begin{array}{l}\text { At 6 months } \\
\text { No of eyes (\%) }\end{array}$ & $\begin{array}{l}\text { At 12 months } \\
\text { No of eyes (\%) }\end{array}$ & $\begin{array}{l}\text { At 18 months } \\
\text { No of eyes (\%) }\end{array}$ & $\begin{array}{l}\text { At 24 months } \\
\text { No of eyes (\%) }\end{array}$ \\
\hline $\begin{array}{llll}\text { Classic CNV group: } \\
\quad 3 / 6(50)\end{array}$ & $3 / 5(60)$ & $1 / 2(50)$ & $1 / 2(50)$ \\
$\quad$ Improved & $2 / 6(33.3)$ & 0 & 0 & 0 \\
$\quad$ Stable & $1 / 6(16.7)$ & $2 / 5(40)$ & $1 / 2(50)$ & $1 / 2(50)$ \\
$\quad \begin{array}{llll}\text { Decreased } \\
\text { Occult CNV group: }\end{array}$ & & & & \\
$\quad$ Improved & $66 / 165(40)$ & $34 / 106(32.1)$ & $17 / 66(25.7)$ & $11 / 40(27.5)$ \\
$\quad$ Stable & $57 / 165(34.5)$ & $49 / 106(46.2)$ & $26 / 66(39.4)$ & $14 / 40(35)$ \\
$\quad$ Decreased & $42 / 165(25.5)$ & $23 / 106(21.7)$ & $23 / 66(34.9)$ & $15 / 40(37.5)$ \\
Mixed CNV group: & & & & \\
$\quad$ Improved & $14 / 60(23.3)$ & $16 / 43(37.2)$ & $10 / 24(41.7)$ & $6 / 13(46.1)$ \\
$\quad$ Stable & $30 / 60(50)$ & $15 / 43(34.9)$ & $5 / 24(20.8)$ & $1 / 13(7.8)$ \\
$\quad$ Decreased & $16 / 60(26.7)$ & $12 / 43(27.9)$ & $9 / 24(37.5)$ & $6 / 13(46.1)$ \\
Global results: & & & & \\
$\quad$ Improved & $83 / 231(36)$ & $53 / 154(34.4)$ & $29 / 94(30.9)$ & $18 / 55(32.7)$ \\
$\quad$ Stable & $89 / 231(38.5)$ & $64 / 154(41.6)$ & $31 / 94(33)$ & $15 / 55(27.3)$ \\
$\quad$ Decreased & $59 / 231(25.5)$ & $37 / 154(24)$ & $34 / 94(36.2)$ & $22 / 55(40)$ \\
\hline
\end{tabular}

and $32.7 \%$ of the eyes at 24 months. At the same time, a significant loss was found in $36 \%$ and $40 \%$ of the eyes, respectively. The relative frequencies of improved or decreased VA were similar at $6,12,18$, and 24 month visits. The percentage of patients complaining of metamorphopsia was statistically lower 6 and 12 months after radiotherapy $(\mathrm{p}=0.01)$, and similar 18 and 24 months after compared with the baseline values (paired comparisons).

Visual outcome was compared in the classic, occult, and mixed CNV groups (Table 2. The difference of the logMAR between baseline and each visit was not statistically different in the occult CNV group compared with the

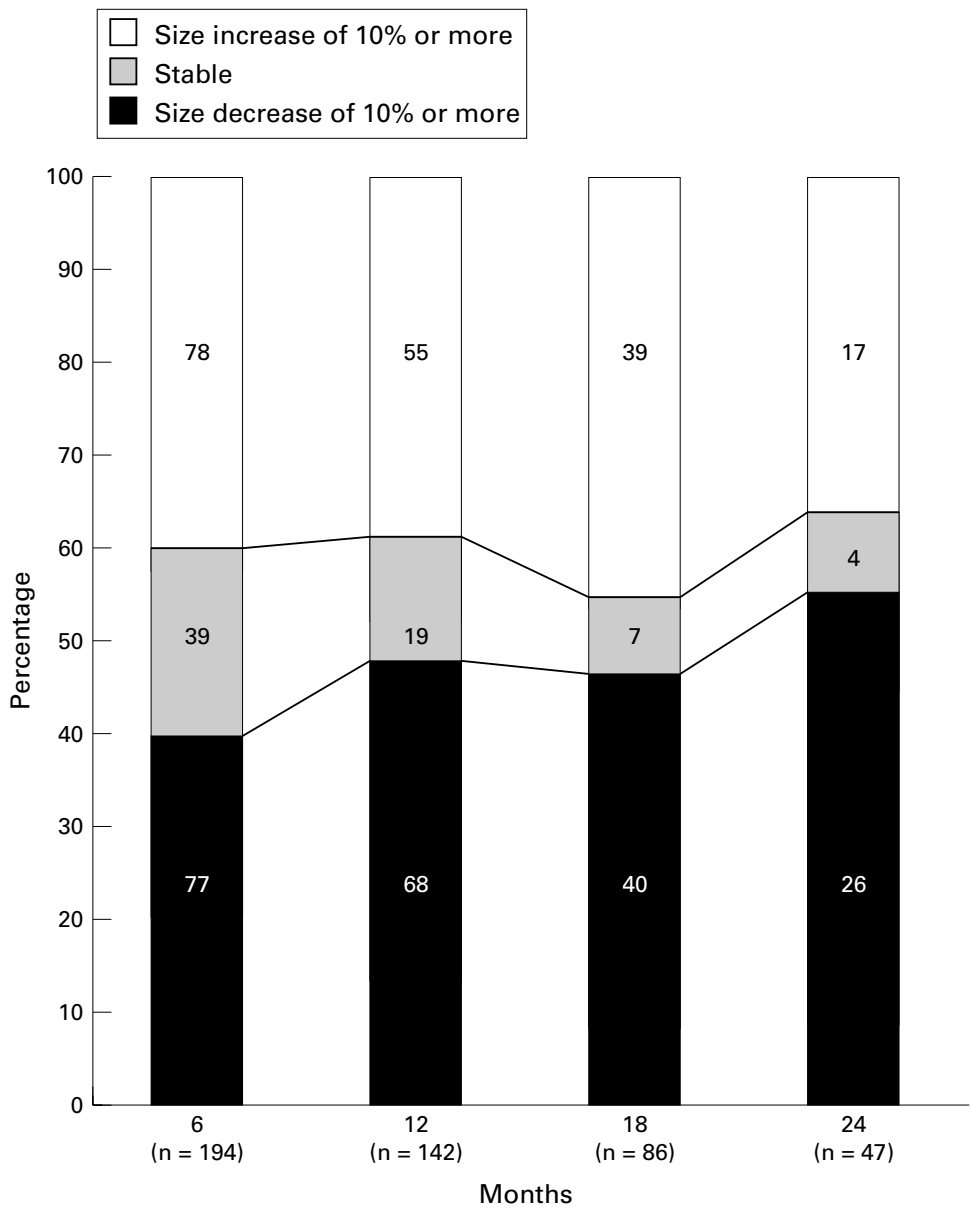

Figure 1 Distribution of eyes with decrease of CNV size in ICG angiography. mixed CNV group. The number of patients with classic $\mathrm{CNV}$ was too small to allow any comparison.

At inclusion, PED was present in $36 \%$ $(83 / 231)$ of the eyes. There was no statistical difference in mean VA at initial, 6, 12, and 18 month visits in patients with or without initial PED. Twenty four months after treatment the mean VA was lower in the group of patients initially diagnosed with associated PED $(\mathrm{p}=$ 0.03). The mean VA changes (final logMAR initial $\log$ MAR) in these two groups of patients were similar at each visit.

Contrast sensitivity was measured in 44 consecutive patients included at the end of the study. Fifty per cent (22/44) and 37.5\% (9/24) of the patients improved their contrast sensitivity at the 6 and 12 month follow up visits, respectively, compared with the initial data. However, these changes were not statistically significant.

CHANGES OF CNV SIZE AFTER RADIOTHERAPY

Paired comparisons of CNV areas in FA and ICG showed no significant change between baseline and each visit. Distribution of eyes with $10 \%$ or more reduction of CNV size compared with baseline values is presented in Figure 1 . Both 12 and 18 months after treatment, $47 \%$ of the eyes showed $10 \%$ or more reduction of CNV size in FA as well as in ICG. When post-treatment measurements of CVNsize were normalised relative to the initial size $(100 \%)$, the median size of CNV membranes in FA after $6,12,18$, and 24 months was $93 \%$, $77 \%, 100 \%$, and $60 \%$, respectively. In ICG, similar results were noted: $100 \%$ at 6,12 , and 18 months, and $74 \%$ at 24 months. When considering specifically the occult CNV group, the median size at $6,12,18$, and 24 months was $93 \%, 80 \%, 103 \%$, and $65 \%$ in FA and $98 \%$, $90 \%, 85 \%$, and $85 \%$ in ICG. In the mixed CNV group, the median size at the same times was $97 \% 70 \%, 83 \%$, and $100 \%$ in $\mathrm{FA}$, and $107 \%, 100 \%, 133 \%$, and $60 \%$ in ICG.

RESULTS IN THE TWO RADIOTHERAPY GROUPS At inclusion, there was no significant difference between the two groups of patients treated (lateral arc therapy and minibeam irradiation) in terms of age, sex, frequency of metamorphopsia, VA, and CNV areas (FA and ICG). During the course of the study, comparison of the two groups revealed no significant difference in VA and CNV area changes.

COMPLICATIONS FOLLOWING RADIOTHERAPY Ocular complications occurring after radiation therapy are presented in Table 3. Four patients were diagnosed with homolateral optic neuropathy between 6 and 18 months after completion of radiotherapy. Extensive investigation found no detectable cause, and therefore it was considered that this occurrence was probably related to radiation therapy. In these cases, dose levels of $16 \mathrm{~Gy}$ in four fractions (one eye) and $20 \mathrm{~Gy}$ in five fractions (three eyes) were used. One patient with optic neuropathy recovered without specific treat- 
Table 3 Ocular complications after radiation therapy

\begin{tabular}{|c|c|c|c|c|}
\hline Complications & At 6 months $(n=231)$ & At 12 months $(n=154)$ & At 18 months $(n=94)$ & At 24 months $(n=55)$ \\
\hline Optic neuropathy & 2 (1 LAT, 1 LBT) & 1 (LBT) & & 1 (LAT) \\
\hline Radiation retinopathy & 1 (LAT) & 2 (LAT) & 3 (2 LAT, 1 LBT) & 2 (LAT) \\
\hline Choroidal telangectasia & 1 (LAT) & 1 (LBT) & 1 (LAT) & 2 (1 LAT, 1 LBT) \\
\hline Choroidal haematomas & 2 (LAT) & 2 (LAT) & 2 (LBT) & 1 (LBT) \\
\hline Vitreous haemorrhage & & 1 (LBT) & & \\
\hline Branch retinal vein occlusion & 1 (LBT) & 2 (LBT) & & \\
\hline
\end{tabular}

LAT=lateral arc therapy (159 eyes); LBT=lateral beam technique (72 eyes).

ment within 9 months and the three others had stable features 8 months after diagnosis.

Radiation retinopathy was diagnosed in eight patients treated with dose levels of $16 \mathrm{~Gy}$ in four fractions (four eyes) or $20 \mathrm{~Gy}$ in five fractions (four eyes). Choroidal telangiectasia were observed in ICG images in five patients when treatment with dose levels of $20 \mathrm{~Gy}$ in five fractions was performed. Branch retinal vein occlusion was diagnosed in three patients (one eye $16 \mathrm{~Gy}$, two eyes $20 \mathrm{~Gy}$ ) and there was no indication for photocoagulation. However, examination found no detectable cause of venous occlusion. Mild side effects such as ocular irritation, conjunctivitis, and dry eyes were noted with both radiotherapy techniques, and were treated with symptomatic drugs. No evolutive cataract occurrence was noted in this series. No rubeosis iridis, neovascular glaucoma, severe retinal haemorrhages, or subtotal exudative retinal detachment have been diagnosed in our patients during follow up.

Table 4 Visual function questionnaire (46 patients, 18 months after radiotherapy)

\begin{tabular}{|c|c|}
\hline Question & $\begin{array}{l}\text { Affirmative No of } \\
\text { answers (\%) }\end{array}$ \\
\hline $\begin{array}{l}\text { Subjective vision of th } \\
\text { Don't know } \\
\text { Good } \\
\text { Intermediate } \\
\text { Poor } \\
\text { Very poor } \\
\text { Blind }\end{array}$ & $\begin{array}{l}1(2.2) \\
1(2.2) \\
12(26.1) \\
12(26.1) \\
19(41.3) \\
1(2.2)\end{array}$ \\
\hline $\begin{array}{l}\text { At the present time, ho } \\
\text { Don't know } \\
\text { Good } \\
\text { Intermediate } \\
\text { Poor } \\
\text { Very poor } \\
\text { Blind }\end{array}$ & $\begin{array}{l}\text { ated eye: } \\
1(2.2) \\
8(17.4) \\
8(17.4) \\
19(41.3) \\
10(21.7) \\
0\end{array}$ \\
\hline $\begin{array}{l}\text { When considering the } \\
\text { newspapers: } \\
\text { Don't know } \\
\text { No problem } \\
\text { Some difficulty } \\
\text { Constant difficulty } \\
\text { Extreme difficulty } \\
\text { Impossible to read }\end{array}$ & $\begin{array}{l}\text { ing small print in } \\
1(2.2) \\
2(4.3) \\
4(8.7) \\
9(19.6) \\
8(17.4) \\
22(47.8)\end{array}$ \\
\hline $\begin{array}{l}\text { When considering the } \\
\text { Don't know } \\
\text { No problem } \\
\text { Some difficulty } \\
\text { Constant difficulty } \\
\text { Extreme difficulty } \\
\text { Impossible to write }\end{array}$ & $\begin{array}{l}\text { handwriting: } \\
1(2.2) \\
1(2.2) \\
6(13) \\
16(34.8) \\
7(15.2) \\
15(32.6)\end{array}$ \\
\hline $\begin{array}{l}\text { How would you assess } \\
\text { Don't know } \\
\text { Excellent } \\
\text { Satisfactory } \\
\text { Limited } \\
\text { Poor } \\
\text { Not beneficial }\end{array}$ & $\begin{array}{l}1(2.2) \\
3(6.5) \\
17(37) \\
12(26.1) \\
10(21.7) \\
3(6.5)\end{array}$ \\
\hline $\begin{array}{l}\text { Would you advise this } \\
\text { related macular deg } \\
\text { Don't know } \\
\text { Definitely } \\
\text { Maybe } \\
\text { Probably not } \\
\text { Definitely not }\end{array}$ & $\begin{array}{l}\text { same pattern of age } \\
2(4.3) \\
30(65.2) \\
8(17.4) \\
4(8.7) \\
2(4.3)\end{array}$ \\
\hline
\end{tabular}

VISUAL FUNCTION QUESTIONNAIRE AFTER RADIOTHERAPY

Of the 46 respondents (Table 4 ), 16 patients $(34.8 \%)$ considered their vision after radiotherapy as "good" or "satisfactory". Furthermore, 22 patients $(47.8 \%)$ found their vision significantly or moderately improved after treatment. However, as many as 22 patients $(47.8 \%)$ experienced major difficulties in writing. At the inclusion, the VA of the fellow eyes not treated by radiotherapy was as follows: less than $20 / 200$ in 34 eyes $(74 \%)$ and between $20 / 200$ and $20 / 50$ in 12 eyes (26\%). In these eyes, the mean CNV area (ICG images) was 11.1 disc area $(S D=7.1$, range $0.4-29.7)$.

\section{Discussion}

The natural history of eyes with AMD has shown a poor visual prognosis, especially when $\mathrm{CNV}$ is associated. ${ }^{24}$ The visual prognosis of eyes with AMD depends on the type of CNV both under observation and after laser treatment. ${ }^{9}$ Laser photocoagulation may be effective, but the functional and anatomical outcome depends on the CNV type as well as on its location. Therefore, it is considered that laser treatment of occult CNV should not be recommended. ${ }^{425}$ In a recent study, even treatment of classic CNV in eyes with classic and occult CNV was considered not to be beneficial. ${ }^{9}$

Radiotherapy has been used as an alternative treatment in selected cases of eyes with subfoveal CNV. However, the reported results are controversial. ${ }^{10-1921}$ Comparisons between different studies are difficult, because size of CNV was measured most often on FA, and ICG was infrequently used. ICG analysis allows better assessment of $\mathrm{CNV}^{26}$ and therefore was systematically performed in our series. Many authors-for example, Hart et al ${ }^{14}$ and Finger et $a l^{13}$ emphasised the need for a long follow up in a larger series in order to better assess radiotherapy. This study was therefore conducted with a minimum follow up period of 6 months and a large population has been evaluated at 12,18 , and 24 months.

The results reported in this study are slightly different from those of the first clinical trials. In our series of mainly occult and mixed CNVs, improvement of VA was noted in $34 \%$ and $32 \%$ of eyes at 12 and 24 months after treatment. However, statistical analysis showed no significant difference compared with baseline VA. In a previous study, ${ }^{10} 52 \%$ of 19 patients had improved vision (two or more lines) 12 months after treatment. In 81 eyes treated with palladium-103 ophthalmic plaque brachytherapy or external beam irradiation, ${ }^{13}$ VA of $79 \%$ of the eyes had one or more lines 
improvement 3-18 months after treatment. Bergink et $a l^{11}$ and Churchill et al ${ }^{18}$ reported stable VA in $60-70 \%$ of the patients at 12 month follow up. Nevertheless, these encouraging findings were not confirmed in other series. More recently, in a randomised controlled study in 75 patients, Bergink et al ${ }^{19}$ showed that $30 \%$ of treated patients ( $v 52 \%$ of control patients) had lost three or more lines of VA at 12 month follow up. In one study, VA improvement of one line or more at 12 months was reported in only $13.2 \%$ of patients. ${ }^{17}$ Even worse results were reported in another recent study $^{16}$ in which only $7.2 \%$ of 111 eyes improved by two or more lines with follow up ranging between 1 and 3 years. When compared with historical control groups from the interferon study, ${ }^{27}$ in which $16.2 \%$ of eyes had one or more lines VA improvement, our results suggest that 16-20 Gy radiotherapy (effective dose 24-30 Gy) could stabilise visual acuity at least up to 18 months after treatment.

Evaluation of visual performance may include not only morphoscopic VA but also other tests, such as contrast sensitivity. This test is more appropriate in assessment of visual function related to daily activities. ${ }^{28}$ We used the Pelli-Robson test, which was previously demonstrated as effective in measuring contrast sensitivity $^{23}$ and already used in AMD patients. $^{29}$ In the sample of patients with contrast sensitivity measurement, no significant change after radiotherapy was noted. These are preliminary results concerning only a small series, and should be further analysed.

AMD creates considerable handicap in daily life $\mathrm{e}^{30}{ }^{31}$ because of decreased visual performance. We inquired about the influence of radiotherapy in our patients' daily behaviour, using a simple six item questionnaire. Patients' subjective answers suggested that even 18 months after radiotherapy they were heavily restricted in key daily activities. For instance, $65 \%$ and $50 \%$ of patients were unable to read or write, respectively. Forty three per cent of the patients were satisfied after radiotherapy, but these results should be qualified by the fact that untreated eyes experienced a poor functional and anatomical outcome. Furthermore, the follow up of the treated eye is not long enough to permit comparisons with the untreated eye.

In this study, analysis of radiotherapy effects covered evolution of the anatomical features besides functional status. Assessment of CNV areas in FA and ICG indicated the possibly beneficial effect of radiation treatment on CNV growth. Nevertheless, our results were less encouraging than those of previous published series. For instance, Chakravarthy et al ${ }^{10}$ reported $83 \%$ regression of CNV at 12 months and $91 \%$ at 18 months, on FA. In another study, ${ }^{16}$ progression of the median size of CNV membranes was noted after radiotherapy, both in classic (264\% growth of the original size after 1 year) and occult (134\%) groups. In other respects, like Bergink et al, ${ }^{11} 1932$ our findings suggested stabilisation of $\mathrm{CNV}$ expansion after radiotherapy.

At the present time, the exact dose of radiation required to treat $\mathrm{CNV}$ in humans is not yet defined. With the lateral beam technique, a dose level of 5 Gy has been reported to be associated with increase of CNV measured in FA after 6 months, even though the VA remained unchanged. ${ }^{12}$ In this study, 8 Gy radiotherapy resulted in no change of VA and CNV sizes. Similarly, no efficacy was noted with a single fraction of $8 \mathrm{~Gy} .{ }^{11}$ Doses of $10 \mathrm{~Gy}$ in five fractions were not found effective in a recent study. ${ }^{17}$ Higher dose levels of radiotherapy (10-15 Gy in five fractions, 24 Gy in six fractions) were reported to have a therapeutic effect. ${ }^{1014}$ Our results after 20 Gy radiotherapy (4 Gy fractions, equivalent dose of $30 \mathrm{~Gy}$ ) are not consistent with previously reported dose levels, ${ }^{16}$ but the dose fractions were different (2 Gy fractions-that is, an equivalent dose of $20 \mathrm{~Gy}$ ). A significant difference of effective dose in these studies could explain the conflicting results.

Tolerance of radiotherapy was also investigated in the present study. Optic neuropathies and retinal vasculopathies probably related to radiation were diagnosed in four and eight patients, respectively. The doses ranged between 16 and $20 \mathrm{~Gy}$ in five fractions. Radiation optic neuropathy has been described within a total dose of 45-50 Gy but a single dose of 7 Gy or more can lead to nerve demyelination, resulting in blindness. ${ }^{33}$ As fraction size appears to be correlated with the risk of occurrence of optic neuropathy, ${ }^{34}$ the fractions used in this study could explain the higher frequency of this complication. The risk of retinal vasculopathy increases with fraction size, ${ }^{17}$ especially for doses higher than $40 \mathrm{~Gy} .^{33} 35$

Pathogenesis of CNV growth remains unclear. Radiotherapy could minimise size and intensity of CNV proliferation. Focal radiotherapy has been reported to limit the proliferation of granulation tissue and markedly reduce inflammatory cell recruitment in an animal model of perforating ocular injuries. ${ }^{36}$ Chronic lesions due to radiotherapy include obliteration of capillary bed and thickening of vascular walls. ${ }^{33}$ As a result, normal tissue is replaced by fibrosis. These cellular effects could explain the inhibitory effect on angiogenesis.

In conclusion, compared with the natural evolution of subfoveal CNV, our prospective study suggests that radiation therapy could stabilise both the anatomical and visual outcome until 24 months after radiation. Further randomised clinical trials are needed to conclude to a beneficial influence of radiotherapy on visual and anatomical outcome and to identify visual predictive factors after radiotherapy.

The authors thank Eric Morignat (Centre Hospitalier LyonSud) for his assistance with the statistical analysis and for managing the visual function questionnaire.

1 Grey RHB, Burns-Cox CJ, Hughes A. Blind and partially sighted registration in Avon. Br f Ophthalmol 1989;73:98894.

2 Thompson JR, Rosenthal AR. Recent trends in the registration of blindness and partial sight in Leicester. $\mathrm{Br} \mathcal{F}$ Ophthalmol 1989;73:95-9.

3 Bressler NM, Bressler SB, Fine SL. Age-related macular degeneration. Surv Ophthalmol 1988;32:375-412.

4 Macular Photocoagulation Study Group. Krypton laser photocoagulation for neovascular lesion of age-related 
macular degeneration: results of a randomized clinical trial. Arch Ophthalmol 1990;108:816-24.

5 Macular Photocoagulation Study Group. Argon laser photocoagulation for neovascular maculopathy. Five years' results from randomized clinical trials. Arch Ophthalmo 1991;109:1109-14

6 Macular Photocoagulation Study Group. Subfoveal neovascular lesions in age-related macular degeneration: guidelines for evaluation and treatment in the macular photocoagulation study. Arch Ophthalmol 1991;109:1242-57.

7 Macular Photocoagulation Study Group. Visual outcome after laser photocoagulation for subfoveal choroidal neovascularization secondary to age-related macular degeneration. Arch Ophthalmol 1994;112:480-8.

8 Macular Photocoagulation Study Group. Argon laser photocoagulation for senile macular degeneration: results phot candomized clinical trial. Arch Ophthalmol 1982:100: 912-18.

9 Macular Photocoagulation Study Group. Occult choroidal neovascularization. Influence on visual outcome in patients with age-related macular degeneration. Arch Ophthalmo with age-related

10 Chakravarthy U, Houston RF, Archer DB. Treatment of age-related subfoveal neovascular membranes by teletherapy: a pilot study. Br f Ophthalmol 1993;77:265-73.

11 Bergink GJ, Deutman AF, Van Den Broek JFCM, et al. Radiation therapy for subfoveal choroidal neovascular membranes in age-related macular degeneration. Graefes Arch Clin Exp Ophthalmol 1994;232:591-8.

12 Valmaggia C, Bischoff P, Ries G. Low dose radiation on the suboveal neovascular membranes in age-related macular degeneration. Klin Monatsbl Augenheilkd 1995;206:343-6.

13 Finger PT, Berson A, Sherr D, et al. Radiation therapy for sub-retinal neovascularization. Ophthalmology 1996;103: 878-89.

14 Hart PM, Chakravarthy U, MacKenzie G, et al. Teletherapy for subfoveal choroidal neovascularization of age-related macular degeneration: results of follow-up in a nonmacular degeneration: results of follow-up in a

15 Hollick EJ, Goble RR, Knowles PJ, et al. Radiotherapy treatment of age-related subfoveal neovascular membranes treatment of age-related subfoveal neovascular me

16 Stalmans P, Leys A, Van Limbergen E. External beam radiotherapy (20 Gy, 2 Gy fractions) fails to control the growth of choroidal neovascularization in age-related macular degeneration : a review of 111 cases. Retina 1997; 17:481-92.

17 Spaide RK, Guyer DR, McCormick B, et al. External beam radiation therapy for choroidal neovascularization. $O p h-$ thalmology 1998;105:24-30.

18 Churchill AJ, Franks WA, Ash DV. An alternative and more cost effective method of delivery of radiotherapy in age related macular degeneration. Br f Ophthalmol 1998;82. 373-5.

19 Bergink GJ, Hoyng CB, van der Maazen RWM, et al. A randomized controlled clinical trial on the efficacy of radiation therapy in the control of subfoveal choroidal neovascularitherapy in the control of subfoveal choroidal neovascularization in age-related macular degeneration: radiation ver236: $321-5$.

20 Jaakkola A, Heikkonen J, Tommila P, et al. Strontium plaque irradiation of subfoveal neovascular membranes in age- related macular degeneration. Graefes Arch Clin Exp Ophthalmol 1998;236:24-30.

21 Augsburger JJ. External beam radiation is not effective in the reatment of age-related macular degeneration. Arch Ophthalmol 1998;116:1509-11.

22 Early Treatment Diabetic Retinopathy Study Research Group. Early treatment diabetic retinopathy study design and baseline patient characteristics. ETDRS report number 7. Ophthalmology 1991;98:741-56.

23 Pelli DG, Robson JG, Wilkins AJ. The design of a new letter chart for measuring contrast sensitivity. Clin Vis Sci 1988;2:187-99.

24 Bressler NM, Frost LA, Bressler SB, et al. Natural course of poorly defined choroidal neovascularization associated with macular degeneration. Arch Ophthalmol 1988;106: 1537-42.

25 Soubrane G, Coscas G, Français C, et al. Occult subretinal new vessels in age-related macular degeneration. Natural history and early laser treatment. Ophthalmology 1990;97: history and.

26 Guyer DR, Yannuzzi LA, Slakter JS, et al. Classification of choroidal neovascularization by digital indocyanine green videoangiography. Ophthalmology 1996;103:2054-60.

27 Pharmacologic Therapy for Macular Degeneration Study Group. Interferon alpha-2a is ineffective for patients with choroidal neovascularization secondary to aged-related macular degeneration: results of a prospective randomized placebo-controlled clinical trial. Arch Ophthalmol 1997; 115:865-72.

28 Owsley C, Sloane ME. Contrast sensitivity, acuity, and the perception of "real-world" targets. $\mathrm{Br} \mathcal{F}$ Ophthalmol 1987;71:791-6

29 Roesen B, Scheider A, Kiraly A, et al. One-year results after radiotherapy of choroidal neovascularization in age-related macular degeneration. Ophthalmologe 1998;95:461-5.

30 Williams RA, Brody BL, Thomas RG, et al. The psychosocial impact of macular degeneration. Arch Ophthalmol 1998;116:514-20.

31 Mangione CM, Berry S, Spritzer K, et al. Identifying the content area for the 51-item National Eye Institute Visual Function Questionnaire: results from focus groups with visually impaired persons. Arch Ophthalmol 1998;116:22733.

32 Bergink GJ, Hoyng CB, Van der Maazen RWM, et al. Visual acuity and scar size in eyes with age-related subfoveal choroidal neovascular lesions, 30 months after radiation therapy. Doc Ophthalmol 1996;92:61-75.

33 Gordon KB, Char DH, Sagerman RH. Late effects of radiation on the eye and ocular adnexa. Int $\mathcal{F}$ Radiation Oncol Biol Phys 1995;31:1123-39.

34 Harris JR, Levene MB. Visual complications following irradiation for pituitary adenomas and craniopharyngiomas. Radiology 1976;120:167-71.

35 Parsons JT, Bova FJ, Fitzgerald CR, et al. Radiation retinopathy after external beam: analysis of time-dose factors. Int 7 Radiation Oncol Biol Phys 1994;30:765-73.

36 Chakravarthy U, Gardiner TA, Archer DB, et al. A light microscopic and autoradiographic study of non-irradiated and irradiated ocular wounds. Curr Eye Res 1989;8:337-48. 